\title{
Hepatitis B Reactivation, CTCAE
}

National Cancer Institute

\section{Source}

National Cancer Institute. Hepatitis B Reactivation, CT CAE. NCI Thesaurus. Code C143211.

A disorder characterized by the reactivation of hepatitis B virus. 